\title{
The self-shaping brain and addiction
}

\author{
Grant Gillett* \\ Bioethics Centre, University of Otago, Otago, PO Box 913, Dunedin New Zealand
}

The role of brain functions in addiction seems, at first glance, straightforward: there is a receptor system for some biochemical agent and a target level of acceptable dose is "clocked" by the system and comes to be aimed at as a level to be achieved homeostatically. The problem then seems to be as to how to biologically disrupt or "fool" this loop at a level by using some bioactive agent or technique that does not interfere damagingly with the physiology of the organism. But the messy world of addiction and the human role in its genesis and continuance suggests that the story may be a little more complex; indeed the evident role of difficult to quantify factors like religious observance of certain kinds only clouds the picture even more and thus renders addiction and its complex cerebral profile in need of penetrating conceptual analysis in terms of the philosophy of medicine.

Kant's Anthropology from a pragmatic point of view (1978, "A") ${ }^{1}$ is a remarkable work that complicates the discussion of brain function, human reason, and human actions and prefigures existential, phenomenological, and post-structuralist problematisations of human self-knowledge by announcing themes Foucault $\left(2008^{22}\right.$ which acknowledge that limning the mind is complicated by the fact that any such study must note that what is discovered includes procedures and connections introduced into our own minds"(A, 17). Human psychology is linked not only to phenomena such as communicability, inter-subjectivity, self-presentation, and sociality but also valorisation and the need to construct what can be construed as a worthwhile self through a process Hacking has called (the looping effect of human kinds [1].

That focus is, in many ways, as fundamental to any philosophically astute study of human psychology and psychopathology as the individualistic humanist focus that displaces the unscientific transcendental post-Cartesian inquiry that underpins dualism. Kant problematizes self-knowledge and his worries are deepened through Foucault's focus on a lived public reality under multiple influences not all of which are definable. The relevant interactions may be "fuzzy" and Foucault's anti-humanism sensitises readers to our participation in a context using techniques we develop as agents in a nexus of powerknowledge inscribed by an almost chaotic structure of discourses and disciplines with an historical placement that is somewhat surd.

Foucault's human being is an organism about which a natural or scientific description can be constructed but that description must be inflected by recognising that a human being is also a creature who exhibits (as Kant has it) "spontaneity" - autopoietic activity shaping both the tools of description and the techniques according to which they are used. This inflexion is philosophically relevant to self-esteem and persistent patterns of action and exhibits a curious cognitive relations between subject, object, and world [2]. Kant's thinker is a quasi-rational product of both rules and judgment so that self-knowledge is not only

${ }^{1}$ Hereinafter A.

${ }^{2}$ Hereinafter $\mathrm{F}$. self-discovery (p94) but also self-formation according to "concepts of perfection which we may always approach but never completely attain" (A 94). That Foucauldian twist focuses on the engaged discursive subject who creates both the tools of analysis and the phenomena of experience within a trajectory through a natural and social world that itself discursively forms a ("third thing") of shared human experience as a context of adaptation. The resulting psycho-biological complex is likely to generate epistemic mistakes about the genesis of things because of problems of self-esteem complicating the point of view. Because it may include the subject's cognitive models of selves of different kinds in selfformation. Hacking conveys the key ideas in two "slogans": 'making up people', referring to the ways in which a new scientific classification may bring into being a new kind of person, conceived of and experienced as a possible contemporary way to be a person; the second, the 'looping effect', refers to the way in which a classification may inter-act with the people classified.

The resulting philosophical position generates an approach to human behaviour and its disorders that is both scientific-analytic or objective and rational but also grounds a critical analysis of the structures of human experience in a life-world [3]. The analysis acknowledges the thinking subject in composing and framing the relevant thoughts rather than just reporting them (introspectively perhaps). Within Kant's Anthropology, the study of the human capacity for reason and freedom avoids both an amalgam of introspection and quasi-scientific psychology. His move avoids two flawed ideas: the idea that introspection reveals a privileged view of the world of inner sense and its truths about ourselves seen transparently and that the states we introspect might have fixed causal roles in a contingent and descriptive or value free psychological economy. In fact the entanglement of self-creation and self-presentation means that a psychological parallel to physiology, is mistakenly based on a false objectification of the human subject (who is not merely an observed object but rather an interested participant in the work of creating him or herself) and not just "what nature makes of man". A more realistic and demanding task acknowledges that a human "makes, can, or should make" something of him/herself in the midst of a complex interwoven array of neurophysiological interactions that are not linear and causal but rather holistic and "looping" $[1,4]$. The reflective self-questioning and critical exploration of self-making that in part forms each of us in an image requires a methodology that both analyses what we do make of ourselves and examines how that is motivated and communicatively developed.

${ }^{*}$ Correspondence to: Grant Gillett, Bioethics Centre, University of Otago, Otago, PO Box 913, Dunedin New Zealand, Tel: Tel 643471 6127; E-mail: grant.gillett@stonebow.otago.ac.nz

Received: September 19, 2018; Accepted: September 26, 2018; Published: September 28, 2018 
Kant explores the complexity of self-knowledge and its socially adaptive role through reflection on insanity as a via negative of the inquiry and here his focus on human autopoiesis as an aspect of selfmaking contrasts insanity with sound thinking, sound action, and a sustainable foundation for human function, giving rise to a strand of thought that Foucault uses to illuminate the human condition. If one were to identify a gap in his inquiry, it would be in the area of selfesteem but Foucault noted a convergence between Kant's inquiry and his own post-structuralist reading of the modes of exclusion from right thinking associated with madness. Foucault's reading of the Anthropology relates it to the problem posed by normatively influenced autopoiesis or self-making (and self-presentation) in a psychology and psycho-pathological analysis of the self that examines both the way one appears to oneself and the way one makes oneself.

That analysis integrates the phenomenology of the life-world, the idea of self-making, and human psychology, in a way that prefigures recent theory about non-linear states and relations, the facts of addiction, and a model of consciousness as global (bio-psycho-social) connectivity in the neuro-cognitive workspace as the brain adapts to a complex set of interwoven and sometimes not clearly distinguishable demands. Following Freeman and his non-linear dynamics of brain function and its development as a mix of cognitive and biological form we can construct an analysis of the addicted psyche through the idea of embodied cognition in which other than biological homeostasis and mechanistic causal chains noting our need to unpick the idea of sustainable self-worth in a life-world and the delicate path any human being has to traverse along a very tentative and vulnerable trajectory beset by "the slings and arrows of outrageous fortune".

Franz Brentano clarified the logical analysis of psychological function in a way that pointed ahead to our brain science and its opening up of neural network theory which is inherently suited to the task of investigating his analysis [5]. The present context of neuroscience and its departure from (complex) mechanistic models into an understanding of the ecological brain as a system in which a neural network creates sustainable modes of being that bring together diverse and diverse kinds of activity in a discursive world frees us from some of the metaphors that have dominated thinking about addiction. Using findings in dynamic EEG waveform analysis, fMRI, diffusion tensor imaging and pathway mapping and concepts such as coherence and prediction modelling we can now fill out the model in ways partly anticipated by Merleau-Ponty but explored from an adventurous type of neurocognitive thinking found in neural network theory and the dynamics of complex systems $[4,6]$.

An evolutionary approach to neuroscience, sketched by John Hughlings-Jackson formulated as neurology developed at the end of the nineteenth and beginning of the Twentieth Century fits well with this emerging account of dynamic brain pathways and modes of functioning in various cognitive tasks and neurological disorders of consciousness [7]. This neuro-philosophical synthesis prefigured much contemporary work and allows us to explore the complex philosophical and ethical puzzles surrounding addiction and its relation to both cerebral synchrony and connectedness on the one hand and analytically difficult social and political realities on the other [8].

Uniquely human consciousness provides an evolutionary niche for the nexus generating addiction and its scientifically elusive genesis made more tractable when we confine our analysis to narrow neurophysiological terms and mechanistic models of brain function [9]. The neurophysiology does not, however, support a narrowing of attention: "the ventral tegmental area, nucleus accumbens, amygdala and prefrontal cortex via dopaminergic and glutamatergic pathways, constitutes a common pathway by which various drugs of abuse mediate their acute reinforcing effects." This liturgy of neural contributions, if anything, confirms the holistic and higher cognitive process involving network form of neuroscentific analysis required. The authors register certain concerns about simplistic theories of addiction "many drugs produce tolerance with repeated use, in that there is a decrease in the reinforcing properties of the drug, leading to compensatory increases in dosage that can exacerbate neurophysiological alterations prototypical of addiction." But "some drugs, including psychostimulants, also produce an opposing response of inverse tolerance, or sensitization, on selected aspects of behaviour" Thus there is no simplistic model available and we are forced to reopen the "Pandora's box" that is integrative bio-psycho-social medicine and neural network inspired models of human brain function [10].

The current analysis notes that the brain aims for a state in which signals are generated suggesting adaptation and familiarity so that already formulated strategies and adaptive responses are likely to be successful. These are holistic and incorporate (in a network or inclusive way) any and all conditions of the neuraxis, retained as network states, the inclusive neural context in which previous life strategies have carried the organism through are part of the construction of goals at which to aim. The fact that one of the holistically combined inputs to this system may be chemical/pharmacological means that a dynamic aspect of behavioural adaptation to our complex psycho-social selfconfiguration in seeking to reproduce the conditions of previous behaviour might involve some contingent previously included chemical element (such as alcohol or a psycho-stimulant).

Such adaptive neural states are holistic and not exclusively biomedical so that along with the ideas and difficult to encode social conditions there are chemical signals and settings which play a part in the state potentiating behavioural adaptation being aimed at. In certain social settings, these chemical signals will include physiological contributions of drugs of abuse but they will also include social and recreational settings which contribute to the network configuration.

That state is supported by ongoing patterns of familiarity and athome-ness in which the individual feels Heimlich or at home, in a comfortable place in the life-world where well-rehearsed patterns of behaviour can be produced. Addiction, on that view would be the need for a chemically active substance to be part of the whole in which the individual feels at home and capable and that could be contributed to by diverse conditions including the need for assurance that things are likely to go well. This could be undermined by persistent failure, by negative ideas, by a context in which all socialisation is supported by substance use, or a situation of felt inadequacy to the unknown challenges that might lie ahead.

When seen through the lens of a neural network and the evolved brain, the brain's physiological state and mental self-monitoring are not at odds in our understanding of what is going on in normal life and mental disorders but both combine to say to the individual concerned either "all is right and likely to go smoothly and predictably to a sustainable conclusion" or that "this is unfamiliar, a disturbing and potentially threatening state that feels alien and could be threatening" $[11,12]$.

Contexts in which all the predisposing conditions combine in a nonformalisable (or holistic) way that depends on feel and familiarity and well-practiced modes of interaction abound in human life (e.g. - sport) and it is no surprise that one of the most vulnerable and prominent 
groups that suffer addictions of one kind or another are sportspeople. Such people suffer the elusive feelings of threat and uncertainty during passages of loss of form and those usher into their psyche the tendency to try and recreate the inchoate conditions of optimal functioning. Those conditions may be elusive and attract some ill-defined characterisations such as "being in the zone" and as they do give the person indefinable and not fully rationalisable or articulable expectations that things will go well perhaps associated with ill-defined fears of failure and perhaps the irrecoverability of a "knack" which may become network-linked to a physiological and pharmacologically generated state. The mechanistic accounts of addiction can cause us to overlook thee autopoietic factors and thus impoverish our synthesis if what is going on.

The inchoate nature of the conditions in which addiction can overcome any person tends to support an open-ended exploration of offsetting conditions such as reassurance - being treated as goodenough, monents of affirmation and self-worth, someone to share the burden of finding - the strength to carry on, and someone to help adapt to - the inarticulate demands of life and normal coping; a narrow biomedical model can blind us and research funders to these things.

The importance of images, aspiration, and imitation in the selfforming brain and the inarticulate nature of the components of the goal that should be aimed at are part of the all-in or holistic well-functioning hinted at by slogans like mens sana in corpore sano but unrecognised by many researchers as they try to frame and get funded research strategies which would illuminate a context of being and affirmation in which one does and does not do certain things but which are not hospitable to definable and denumerable variables.

It is the domain of open-ended inquiry into the traditional resources of humanity as they favour the creation of life-affirming contexts and pathways to success in whatever field of human endeavour that we slip up in the contemporary scientific environment with its industrial underpinning of causal mechanisms and technological (including pharmacological and genetic) medicine. An affirmative love-of-life or even religious context in which human relationships are celebrated and enhanced and every human being is valued is a framework conducive to what Fuchs calls the ecological brain - socially and culturally scaffolded into doing well in a complex context not amenable to narrow analyses (171ff) but accommodating to therapeutic responses that are "emergent and recognise upward and downward causation" (240) and that focus on the body as a site not only of human physiology but also of "lived identity" (290) that broadening of the focus embraces strands of thought more prominent in ethics than in physiology or pathology but makes sense of the diverse approaches to addiction - a task, a mission, a transcendent calling that sweeps one up - which actually do a lot of clinical and epidemiological work. It is not surprising that the relevant ideas are often encountered in religious or quasi-religious contexts in which human life is regarded as "sacred", "a pearl of great price", a context of being pervaded by agape - selfless love. These are not soppy but rather fledgling attempts to render the world of value from which some people have sadly excluded themselves in destructive ways so that it can be a site of rescue.

Aristotle's conception of the soul or psyche as the form of a living body which develops from our first or biological nature as the human being is enculturated or shaped by training (to form a "second nature" - a locus of thought and actions) predicates the value of each human being and their irreplaceable intentionality or cognitive contribution to their world on their development. That can be legitimately included in the analysis of the preconditions for addiction because it explores not only our contact with the objects that we relate to in human forms of life and the broad conditions under which we meet them but also the ways in which as agents we are enabled to surmount the challenges that living a life throws up so that one can legitimately value oneself as having attained or achieved something. That thrust strengthens the intellectual basis of the bio-psycho-social model of medicine as it lays the foundations for a systematic inquiry of value and a neurocognitive investigation of consciousness, human choices, and the sometimes tragic failures we experience. Our embodied being-in-theworld and its normative ("how ought I to act?"), situated, culturally inflected, conditions underpin our practices of exploration and dealing with things and bring forth (in a homely or familiar and confidenceinspiring way) the objects and situations we relate to and think about in our human ethological domain.

Kant and Husserl further our understanding of ourselves as we grapple with objects of thought, the nature of our own intentionality, and our roles in cognition and self-valuing conscious experience, focussing predominantly on intellectual and cultural rules for the understanding of the world. Both the world and what we make of it inflect of cognition in defining objects according to concepts that link situations through techniques of search and interrogation developed in social, interpersonal, and linguistic contexts. They provide a discursive grounding of cognition whereby individuals access a shared cognitive resource constituted by cultural learning and the rules or norms which human beings use to structure thoughts and meanings and refine them through argumentation.

The context of argument is one in which multiple human beings converge in their thought and talk about a third thing, producing what is called triangulation. That context, of intersubjectivity, communication, judgment, and knowledge feeds into the nexus of cerebral connectivity that underpins conscious thought as investigated in cognitive neuroscience. Philosophers after Kant, such as the phenomenologists and a parallel strand of developmental psychology found in Vygotsky and Wittgenstein flesh out the way that human beings are adapted to a normative realm that articulates the structures shaping human thought and experience through training during cognitive development (as Aristotle realised) [13-15]. The connections to embodiment, culture and human cognition are not merely a matter of manipulating abstract formulae but also underpin doing things in the world and learning to deal with the many challenges that our mortality throws in our way an area in which we need more (not less) scholarship exploring the philosophy of medicine in an increasingly scientific and technological age.

John Hughlings-Jackson (JHJ) developed a phylogenetic and ontogenetic theory of human neural development focusing on the holistic integration and coordination of sensori-motor functions as the basis of higher mental life. He also noted the remarkable role of "propositionising" or a the language of reasoning and discourse in human brain function. The integration he outlined wencompassed wider and more inclusive information about a situation which the human neural net (as we would now call it) gathered and made use of to organise a repertoire of holistic responses to the challenges posed to any human being. The result is consciousness, implicating memory, reason, emotion, and will in the structures holistically coordinating human adaptation to our constructed world. Consciousness seen this way is captured by the weighted Symbolic Mutual Information measure developed recently in neuroimaging and it is realised by acquired patterns of information broadcast throughout a global neuro-cognitive workspace. 
Human case "propositionising" the use of a shared system of semantic signs tied to truth and falsity and the use of reason, introduces an aspect to human thought that lifts our adaptation to a new level. Using triangulation between intelligent subjects and the world and maximally inclusive intersubjective communication we develop a shared imaginary construction of (or set of predictions about) the world cooperatively developed and refined by multiple agents and checked out for errors within a quasi-objective domain where truth plays a central role in thought and understanding. Such a neo-Fregean analysis of content can be interpreted according to Wittgenstein's naturalistic philosophical anthropology and allows us to further elaborate the idea of an Objective-Reflective-Normative domain or "space of reasons" within which second nature is shaped as a coordinated set of skills for dealing with the world. The resulting framework connects closely to work on concepts and consciousness as detailed within a VygotskyLuria account of thought, language, and the neuro-psychological origins of contemporary cognitive neuroscience [12]. The view that emerges potentially solves a number of problems about meaning and human mental life in a way that has obvious conceptual links to Wittgenstein's broader philosophical psychology.

The resulting theory of brain function has diverse links: with poststructuralist, or structural empiricist analyses especially of non-linguistic thought as in sport, art, sociality, and music; with Electro-corticography data; with work on cerebral synchrony in perceptual and conscious processing; with wSMI imaging of neuro-cognitive processing; and with the Predictive brain as an implicit solution to the binding problem and as a way of understanding the intentional arc central to embodied approaches to phenomenology $[16,17]$. An account of the intentional arc understood in terms of cerebral connectivity and integrated holistic coupling to a domain of agency generates a useful analysis of human experience in the real world, and human disorders as they are explored by some neuroethical analyses (Fuchs, 2018). That is not favourable to standard causally based analyses in terms of definable dependent and independent variables but may, in fact, be non-negotiable as we try to link addiction and the brain in lived human lives.

\section{References}

1. Hacking (2007) Proceedings of the British Academy. The British Academy 151: 285318 .

2. Davidson L, Cosgrove LA (1991) Psychologism and Phenomenological Psychology Revisited Part I: The Liberation From Naturalism. Journal of Phenomenological Psychology 22: 87-108.

3. Husserl E (1954) The crisis of European sciences and transcendental phenomenology (Carr Trans D). Chicago: Northwestern University Press.

4. Freeman WJ (2008) A pseudo-equilibrium thermodynamic model of information processing in non-linear brain dynamics. Neural Netw 21: 257-265. [Crossref]

5. Brentano F (1929) Sensory and noetic consciousness. Schattle M, McAlister L (Eds).

6. Gillett G (2018) From Aristotle to cognitive neuroscience: The human soul. Palgrave McMillan, London.

7. Hughlings-Jackson (1884) Croonian lectures on the evolution and dissolution of the nervous system. Br Med J 1: 660-663. [Crossref]

8. Franz EA, Gillett G (2011) John Hughlings Jackson's evolutionary neurology: A unifying framework for cognitive neuroscience. Brain 134: 3114-3120. [Crossref]

9. Feltenstein MW (2008) The neurocircuitry of addiction: an overview. Br J Pharmacol 154: 261-274. [Crossref]

10. Engel J (1977) The need for a new medical model poses a challenge for biomedical science. Science 196: 129-136. [Crossref]

11. Fuchs T (2018) The Ecological brain. Oxford: University Press.

12. Gillett G (2008) Subjectivity and being somebody: Human identity and neuroethics (St Andrews Series on Philosophy and Public Affairs). Exeter: Imprint Academic.

13. Vygotsky LS (1962) Thought and language (Hanfmann E, Vakar G) MA, Cambridge.

14. Luria AR (1973) The working brain. Harmondsworth: Penguin.

15. Wittgenstein L (1953) Philosophical investigations. Anscombe GEM (Ed) Oxford: Blackwell.

16. Hacking I (1995) Rewriting the Soul: Multiple Personality and the Sciences of Memory, Princeton.

17. Kosma, Davies, Freenan, Engel (2012) The need for a new medical model poses a challenge for biomedical science. Science 196: 126-129.

Copyright: (C2018 Gillett G. This is an open-access article distributed under the terms of the Creative Commons Attribution License, which permits unrestricted use, distribution, and reproduction in any medium, provided the original author and source are credited. 